\title{
Monetary Stabilization Policy in the Coronacrisis
}

\author{
Tatiana Kotcofana ${ }^{1, *}$, Anastasiya Titova $^{1}$, and Armen Altunyan ${ }^{1}$ \\ ${ }^{1}$ Saint-Petersburg State University, Faculty of Economics, Universitetskaya emb. 7-9, Saint-Petersburg, \\ Russia
}

\begin{abstract}
Research background: In 2020, all the world's economies faced a new, special phenomenon - the coronacrisis caused by the pandemic, and with the fall of most economic indicators. In the current conditions, it is extremely important to build a competent monetary policy in order to soften the "blows" caused by the global recession for national economies.

Purpose of the article: The main purpose of the presented article is the analysis of measures to stimulate the economy using monetary policy instruments in the conditions of the coronacrisis.

Methods: To conduct the study, we used official statistics data, on the basis of which an econometric model was built, which allowed us to determine the forecast values for inflation, taking into account the impact of monetary and non-monetary factors.

Findings \& Value added: The econometric analysis show the high importance of non-monetary factors of inflation. This makes it difficult to assess the monetary policy, since Central banks are able to influence nonmonetary factors only indirectly. The paper notes the influence of the refinancing rate on loans to the real sector of the economy, since the stabilization monetary policy should be primarily aimed at maintaining economic growth. The correlation field of the relationship between the index of rigidity of restrictions developed by the University of Oxford and loans to small and medium-sized businesses is constructed. It is noted that with the reduction of administrative restrictions, the volume of loans granted to small and medium-sized businesses increases.
\end{abstract}

Keywords: monetary stabilization policy; Coronacrisis; inflation; refinancing rate

JEL Classification: E31; E43; E52

\section{Introduction}

In 2020, the world's economies faced a new, special phenomenon in the global economy the coronacrisis caused by the pandemic. The COVID-19 crisis have revealed the limits of a conventional model of economic growth. (Leach et al., 2021) Economic uncertainty has radically increased, which is confirmed by the research of Altig et al. (2020)

* Corresponding author: author@email.org 
The long-term consequences of the COVID-19 crisis have not yet been fully assessed, but the first estimates do not inspire optimism. So, Auerbach et al. (2021) show that COVID restrictions can reduce current-period GDP by more than is directly associated with the restrictions themselves when rigid capital costs induce firm exit. Furthermore, COVID19 restrictions can cause future inflation, as households tilt their expenditure toward the future.

Traditional macroeconomic stabilization policies seek to moderate swings in economic activity through measures that primarily augment aggregate demand. Such measures are, however, inadequate in mitigating the comprehensive effects of crisis such as the COVID19, which affects both the demand and supply sides of the economy (Braunerhjelm, 2021).

In the current conditions, it is extremely important to build a competent monetary policy in order to mitigate the "blows" caused by the global recession. The introduction of anti-crisis measures by the Bank of Russia makes it necessary to build forecast values of the main economic indicators.

\section{Methods}

This study presents data for the period from September 2013 to March 2021. To construct the equations, correlation and regression analysis is used, namely the least squares method (OLS), since in this case it is the most suitable. As a result, using OLS, equations of different models will be obtained for compiling a common system. In the author's opinion, in this case, since the variables are consistently dependent on each other, but the initial one does not affect the final one, it is the system of equations that will help to describe in more detail the formation of the inflation rate in the Russian Federation from other indicators than just a regression model. For example, such indicators as retail trade turnover and the industrial production index directly originate from each other, as well as the consumer price index.

\section{Results and Discussions}

\subsection{The Bank of Russia and the basic principles of monetary regulation}

The Bank of Russia is an independent organ responsible for the implementation of monetary policy measures, with its own goals, objectives, functions, methods and tools. According to Moiseev (2018), the independence of monetary instruments, which implies freedom of choice in the conduct of monetary policy, is one of the levels of independence in monetary policy, along with the independence of the goals of the policy and operational independence in the choice of intermediate and operational goals.

The goal of the Bank of Russia is to maintain consistently low inflation, which is ensured with price and financial stability. The central bank sets the target for the annual growth rate of consumer prices at $4 \%$, but some deviations are acceptable. In the event of a significant fluctuation in the inflation rate, the Central Bank takes measures to return to the target. To keep inflation at the target level, the interest rate channel is used, that is, market instruments, and not administrative measures.

In order to estimate the impact of changes in the key rate on price dynamics, it is necessary to make a forecast based on modern models, taking into account the economic policy of foreign countries, with the most complete assessment of the pro-inflationary factors that increase inflation. Thus, the inflationary expectations of economic entities are taken into account, and the monetary regulator, if necessary, affects the expectations of economic entities. As noted by Petrova and Trunin (2019), inflation expectations in Russia are quite high. According to the Bank of Russia, in March 2021, the population's inflation expectations for the next 12 months increased to $10.1 \%$ (according to the median), compared with 
February 2021, when the same indicator was $9.9 \%$. However, the inflation observed by the population was lower than expected (Information and Analytical Commentary of the Bank of Russia, 2021).

\subsection{Influence of monetary and non-monetary factors on inflation in Russia}

Inflation and inflation uncertainty are critical factors influencing the functioning of markets and thus the efficient flow of economic activities. (Iyke and Ho, 2019)

The central bank cannot always guarantee a positive result of its work on regulating and curbing inflation. In most cases, the influence on the inflation rate is exerted from the outside, by factors that cannot be unambiguously regulated at all, which significantly complicates the Central Bank's ability to influence the inflation rate. This problem can be considered acute, since inflation significantly affects both economic development and the standard of living of the population. Moreover, as the study shows (Ybrayev, 2021), inflation has the most destructive effect on the lower income distribution groups.

We will refer to the monetary factors of inflation those parameters that the Central Bank is able to directly influence and use as a tool, that are, the key rate, the interest rates of the money market, inflation expectations, as well as the rates formed by commercial banks. Nonmonetary factors include those that the Bank of Russia affects indirectly.

The increase in the amount of money should be attributed to monetary factors of inflation (Pitelin, 2015). However, with the advent of more advanced payment methods and new financial instruments, the issue of money as a factor of influence on inflationary processes is fading into the background. There are studies showing that direct lending by the Central Bank to the government or the purchase of government bonds on the primary/secondary market do not carry such a significant threat of inflation, as is declared by the opponents of such a policy (but also does not give such a stimulating effect, as its supporters claim) (Felipe and Fullwiler, 2021).

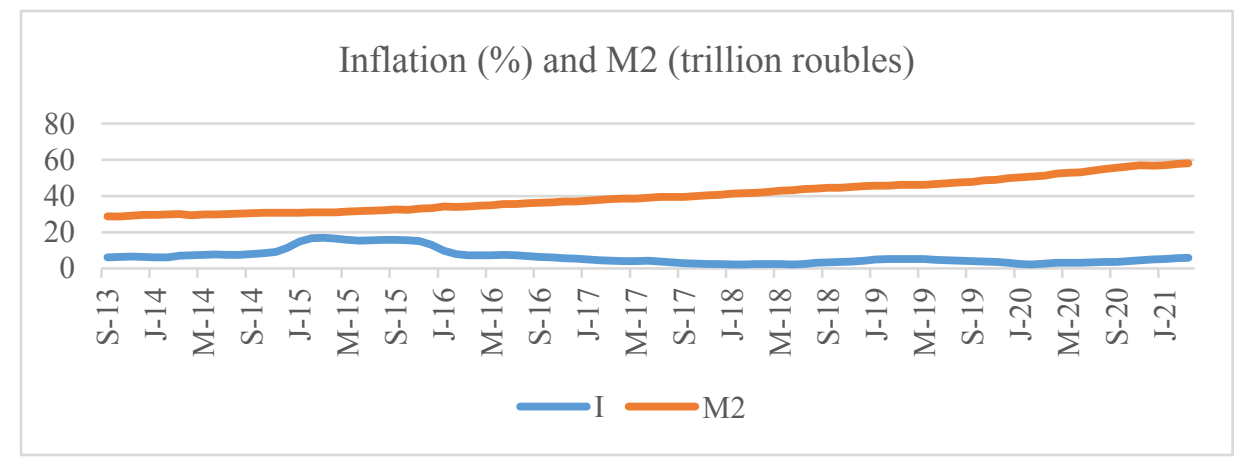

Figure 1. The indicator of the M2 monetary aggregate for the period from September 2013. until January 2021. (in trillion rubles) and inflation for the period from September 2013. until January 2021. (in \%)

Source : compiled by the author at Bank of Russia (https://www.cbr.ru/statistics/ms/)

From the graphical analysis of Figure 1, it can be seen that the monetarist theory is not confirmed in the Russian reality, since the relationship between the growth of the money supply and the inflation rate is rather inverse than direct. This means that the inflation rate is formed mainly under the influence of non-monetary factors. In the Russian conditions, the price growth is influenced by cost factors associated with the monopolization of the economy, the insufficient effectiveness of antimonopoly legislation, the outpacing growth of prices for fuel, energy and raw materials. (Kotcofana et al., 2020). The study (Zhemkov, 2019) showed 
a significant influence of structural factors on the inflation rate, moreover, this influence is extremely heterogeneous in the regional context.

An analysis of the dynamics of the inflation rate in the period from 2015 to 2020 showed that inflation is characterized by high volatility in the Russian economy (the standard deviation is 4.52). Given that the inflation target is $4 \%$, the sample spread is quite high. This is an alarming trend, given that a number of studies show the negative impact of inflation volatility on economic growth. (Hossain and Arwatchanakarn, 2016)

However, at the moment, the indicator of the inflation rate is close to the target. Moreover, there is a tendency to decrease the standard deviation indicator at the present time. The peak was noticed during the crisis of 2014-2015, which is explained by exchange rate shocks. Since 2017, we can note a slowdown in the growth of consumer prices. The minimum values were reached in the first half of 2018. Further, the growth of consumer prices accelerated and reached the target value of $4 \%$. Representatives of the Bank of Russia note that the volatility of inflation is mainly associated with fluctuations in food prices.

It should be assumed that the regulation of factors that to some extent influence the level of inflation can simplify the task of influencing inflation itself. Therefore, it was decided to construct an equation for the formation of a particular level of inflation and the factors that are most significant in this process.

The results of the correlation analysis of the consumer price index and the money supply indicate a close relationship between inflation and the money supply, but the relationship is negative. The correlation is equal to -0.6015 , that is, we can conclude that with the growth of the money supply, inflation will decrease. Based on this, it can be argued that inflation in the Russian Federation is non-monetary in nature.

The real reason for inflation in the Russian economy is the inability of domestic production to serve the growing effective demand of the population, that is, the low level of inflation mainly depends on the harmonious joint development of the effective demand of the population and the level of production in the economy. Thus, through factor analysis, it was revealed that inflation in the Russian economy is formed by non-monetary factors.

First of all, for the further formation of models and the final system of equations, it is necessary to calculate the correlation between all indicators. Since many indicators are correlated with each other, this will help to understand the cause-and-effect relationships and model the layout of the system, as well as eliminate redundant variables at the very first stage and avoid multicollinearity.

Let's highlight the following names of variables.:

$I$ - the rate of inflation;

$r$ - key rate;

$I P I$ - industrial production index;

$T$ - retail trade turnover;

inv - investments in fixed assets;

inc - monetary income of the population;

$U S D$ - dollar to ruble exchange rate;

urals - futures quotes of URALS;

imp - the volume of imports.

Initially, a matrix of paired correlation coefficients should be compiled (see Table 1). Most of the obtained pair correlation coefficients are significant. Several values are insignificant, the closeness of the connection of which is low, that is, they will not take part in further research. Thus, then we can proceed to the consideration of a high degree of correlation between variables and build a model of a system of equations. For the analysis, those variables whose tightness of the connection exceeds the value of 0.5 are taken. Also, to exclude multicollinearity in the compiled equations, interdependent variables in them will be excluded. 
Table 1. Matrix of paired correlation coefficients

\begin{tabular}{|l|l|l|l|l|l|l|l|l|l|}
\hline & IPI & T & I & r & inv & inc & USD & urals & imp \\
\hline IPI & 1 & 0,402 & $-0,231$ & $-0,393$ & 0,011 & 0,354 & $-0,417$ & 0,449 & 0,736 \\
\hline T & & 1,000 & $-0,408$ & $-0,372$ & 0,683 & 0,821 & 0,542 & $-0,320$ & 0,022 \\
\hline I & & & 1,000 & 0,696 & $-0,645$ & $-0,330$ & $-0,144$ & $-0,082$ & $-0,257$ \\
\hline r & & & & 1,000 & $-0,610$ & $-0,307$ & 0,002 & $-0,304$ & $-0,498$ \\
\hline inv & & & & & 1,000 & 0,545 & 0,624 & $-0,297$ & $-0,091$ \\
\hline inc & & & & & & 1,000 & 0,505 & $-0,337$ & 0,031 \\
\hline USD & & & & & & & 1,000 & $-0,768$ & $-0,702$ \\
\hline urals & & & & & & & & 1,000 & 0,764 \\
\hline imp & & & & & & & & & 1,000 \\
\hline
\end{tabular}

Source : compiled by the author

After calculating the coefficients, their significance was checked using the Student's ttest. Based on the results obtained, as well as considering the options for constructing the system, the model of equations looks like this:

$$
\left\{\begin{array}{c}
I=r \\
r=i n v+i m p \\
i n v=T \\
i m p=I P I+\text { urals } \\
T=i n c
\end{array}\right.
$$

In the equations, you can observe the absence of the dollar-ruble exchange rate. Since the variable correlated with most of the others, it was decided to exclude it from the study in order to avoid multicollinearity. It was possible to replace the URALS stock quotes with the dollar-ruble exchange rate, however, according to the author, it is more correct to consider quotes in this analysis.

To begin with, let's consider the equation of the inflation rate itself. Since the level of inflation and the key rate can be considered interdependent, they will be the basis for building the system. The equation looks like this:

$$
I=-2,22+1,03 * r
$$

The coefficients of the model are significant, therefore, there are no unnecessary variables, and we can trust the obtained values of the coefficients for further construction of the system.

Next, we will express the key rate in the same way. Based on the theoretical foundations and the results obtained earlier, this dependent variable is formed from the values of investments in fixed assets, as well as the volume of imports. The equation is as follows:

$$
r=27,64-0,74 * i n v-3,32 * i m p
$$

As in the previous model, the coefficients for regressors are significant, therefore, all variables can be included in further analysis. It is also worth noting that the model is significant in general.

It is worth paying attention to the signs before the coefficients, that is, the nature of the influence of variables on the key rate. Based on the obtained values, with an increase in investments by 1 trillion rubles, the key rate, all other things being equal, decreases by 0.74 , which corresponds to modern market paradigms, since the increasing demand for borrowed funds leads to a reduction in the cost of their maintenance. Also, in the period after the imposition of sanctions and retaliatory measures in the form of counter-sanctions, state 
authorities began to take measures to mitigate the business conditions of domestic producers. In turn, the Central Bank should implement monetary policy in order to reduce the key rate. The availability of loans is increasing, which means that it may not be so profitable for foreign manufacturers to provide their goods and services to the Russian market. Moreover, the growth of domestic production affects the growth of exports, which reduces the share of imports in the balance of payments. Thus, we can talk about the correctness of the obtained model, with an increase in the volume of imports by 1 trillion rubles, the key rate will decrease by an average of 3.32 .

Let's move on to the consideration of the equation of investment in fixed assets. Based on the previously made calculations and the compiled model, investments in fixed assets are formed due to the turnover of retail trade. It is worth noting that despite the connection of trade turnover with investment, trade does not directly affect the rate and inflation. For this reason, the trade turnover was included in the system separately through the connection with investments, since, of course, trade cannot but have an impact on the inflation rate. The equation is as follows:

$$
\text { inv }=4,48+4,8 * T
$$

The obtained coefficients of the model are significant. Thus, the retail trade turnover has a positive effect on investment. The growth of trade turnover leads to an increase in the supply of goods and services, and, consequently, to the need for fixed capital for further expansion or updating of equipment.

Consider the following equation, namely the volume of imports. The regressors in this equation are the industrial production index and the URALS stock quotes. As mentioned earlier, according to the author, based on the subject of the study, it is more expedient to consider oil prices than the dollar-ruble exchange rate. In addition, the matrix of paired correlation coefficients indicates a greater closeness of the import relationship with quotes than with the exchange rate. However, to test the hypothesis, the author also built a model in which the dollar exchange rate acts as a regressor instead of quotes. The resulting model turned out to be worse both in terms of the value of the determination coefficient and in terms of information criteria. Based on this, it was decided to keep the original equation, which looks like this:

$$
\text { imp }=-1,04+2,46 * I P I+0,01 * \text { urals }
$$

The coefficients for regressors are significant, and the model is also significant as a whole. In addition to the positive verification of the correctness of the specification using the Ramsey test, of course, the growth of the industrial production index leads to an increase in the volume of imports.

Let's proceed to the construction of the latest model of retail trade turnover and the derivation of the equation. It is obvious that the turnover of trade depends on the monetary income of the population. The equation of the model looks like this:

$$
T=0,46+6,4 e-05 * i n c
$$

Despite the coefficient value being too low, the model can be considered correct and significant, since the monetary income of the population is a disproportionately small amount compared to the trade turnover. The marginal value of income for the entire period is 43 thousand rubles, while the trade turnover is measured in trillions. Of course, the growth of income by 1 unit cannot significantly affect the turnover.

Thus, it is possible to make a system from the obtained equations: 


$$
\left\{\begin{array}{c}
I=-2,22+1,03 * r \\
r=27,64-0,74 * \operatorname{inv}-3,32 * \text { imp } \\
\text { inv }=4,48+4,8 * T \\
\text { imp }=-1,04+2,46 * I P I+0,01 * \text { urals } \\
T=0,46+6,4 e-05 * \text { inc }
\end{array}\right.
$$

Based on the obtained system, it can be seen that the level of inflation is influenced by many non-monetary factors, but not all of them directly affect it. For example, it was not mathematically revealed that investments in fixed assets form the level of inflation, but investments have a connection with the rate, and it, in turn, with inflation, and so on. Thanks to the obtained system, it was proved that the containment of inflation can be influenced not only by changing the same money supply. By establishing the so-called chain relationship of various indicators and thereby reducing the rate of inflation, it is possible to reduce the effectiveness of monetary policy, as well as by analyzing other effects from the use of different options for influencing the inflation rate in the country, to minimize the harmful impact of interventions on the development of the economy.

Next, it is necessary to test the resulting system of equations. To do this, we take the index of industrial production, the stock price and cash income for a specific period and, substituting the corresponding values in the equation, we determine the level of inflation and compare it with real data.

Consider the data for March 2021, where $I P I=1,063$, urals $=63,62$, a inc $=32612$.

We substitute the available data into the equations $T$ и $і$ imp, then

$$
\begin{gathered}
T=0,46+6,4 e-05 * 32612=2,55 \\
\text { imp }=-1,04+2,46 * 1,063+0,01 * 63,62=2,21 \\
\text { inv }=4,48+4,8^{*} T=16,72 \\
r=27,64-0,74 * 16,72-3,32 * 2,21=7,93
\end{gathered}
$$

Then the inflation rate equals

$$
I=-2,22+1,03 * 7,93=5,95
$$

The actual inflation for March 2021 is 5.78. The calculated value is uncritically different from the actual one, the values are rounded in the equation, which gives an error, and the value is also included in the $95 \%$ confidence interval. Based on all of the above, the approbation of the resulting system can be considered successful and in the future we can trust the system of equations.

\subsection{Application of the Bank of Russia's monetary policy instruments to stabilize the economy}

Having determined the main factors of inflation formation, let's consider what tools the Bank of Russia is able to keep inflation near the target value.

Keeping inflation close to the target level is achieved with the help of the main instrument of the stabilization monetary policy-the key rate, with which the Bank of Russia affects the interbank market rates, as well as the rates on loans and deposits provided by credit institutions (Konyakhina, 2020). Moreover, the key rate is the main indicator of monetary policy.

During the current crisis, the Central Bank decided to pursue a policy of "cheap money". In 2020, the Bank of Russia decided to reduce the mandatory reserve ratio and the key rate, 
which later led to an increase in the number of loans issued to both firms and households. These changes reduce the price of the loan, which leads to an increase in investment. All these measures help to stimulate aggregate demand. As shown above, inflation in Russia is formed by non-monetary factors, so a multiplicative increase in the money supply with monetary stimulation does not increase its level.

\subsection{Econometric model of inflation forecasting}

To conduct an econometric analysis, data were taken on the key rate of the Bank of Russia and the inflation rate by month in the period from 2013 to 2021 . The main purpose of the analysis is to identify the inflationary trend, as well as indicators that have a direct impact on it. Since the level of inflation and the key rate can be considered interdependent, they will be the basis for building a mathematical model. It is worth noting that the Bank of Russia has decided to implement an inflation targeting policy in 2015 . We assume that a change in the conduct of monetary policy may have an impact on the future model.

The variables in the model will be defined as follows:

$I$ - the rate of inflation;

$r$ - the key rate;

$M 2$ - money supply;

$U S D$ - dollar to ruble exchange rate;

GDP - GDP;

urals - quotation of the price of the brand oil URALS.

In our opinion, these variables can best describe the change in the inflation rate and, accordingly, the key rate.

Since the data are heterogeneous, it was decided to prologarithm some of the variables for a clearer analysis and qualitative construction of the model. The variables $r$ and I, namely the key rate and the inflation rate, are the most stable and small values, so it was concluded that it is advisable to logarithm the remaining variables.

The results of the selected model are presented below. It was decided to build a least squares model, since it can best describe the existing sample.

$R$-square is 0.61 , which is a low value, but it indicates the maximum approximation to real data. The P-value of the Fisher criterion indicates its significance, and therefore the significance of the model as a whole. The resulting equation looks like this:

$$
I=75,24+0,35 * r-16,07 * l \_M 2+6,28 * l \_U S D+7,56 * l \_G D P-0,73 * l \_u r a l s
$$

Based on the results obtained, it can be argued that the rate, the dollar exchange rate and GDP have a positive effect on inflation. It was also revealed that the oil price quotation does not affect the inflation rate, therefore, this indicator can be excluded from further analysis. This is confirmed by the results of the test for the presence of redundant variables.

Next, the analysis of time series was carried out according to existing indicators. First of all, we checked the stationarity of the considered series and the order of their integrability. The Dickey-Fuller test was used to determine the order of integrability.

ADF-test for the variable I indicates the non-stationarity of the series. This conclusion is made on the basis of the p-value, which in this case exceeds 0.05 . Tests with the remaining rows also indicate a lack of stationarity. Since the tests indicate the presence of a single root, the first differences of these series were added and tests were performed with them.

$P$-value in the test with the first difference is less than 0.05 , therefore, the process is stationary and there is no single root. The situation is similar with the other rows. We can conclude that the series are first-order integrated series, with the exception of the M2 series, which has a second-order integrability.

Next, an inflation forecasting model was built. To begin with, the order of lags was determined. The maximum lag was assumed to be 24 , since the work considers monthly data. 
To determine which lags are most suitable, several models were built and the best one was selected based on its quality and the values of information criteria. The following options were considered (see Table 2)

All models are stationary and reversible, since the modules of the unit roots are greater than one. Initially, models $1,2,8$ and 9 were discarded, since these models have autocorrelation based on the Leung-Box test. Further, based on the values of the information criteria, it was concluded that it was advisable to use the model 6 . So, it was decided to use the model ARIMA $(1,2,14)$.

The forecast value for the inflation rate for April 2021 is 5.68 . The $95 \%$ confidence interval is in the range from 4.84 to 6.52. The actual inflation in April 2021 was 5.53\%, which is very slightly different from the forecast value and allows us to recognize the testing of the chosen model as successful and use it in the future to predict the inflation rate in the Russian economy.

Table 2. Comparison of inflation forecasting models

\begin{tabular}{|c|c|c|c|c|c|c|}
\hline Model & Lags & $\begin{array}{l}\text { The } \\
\text { Akaike } \\
\text { criterion }\end{array}$ & $\begin{array}{l}\text { The } \\
\text { Schwartz } \\
\text { criterion }\end{array}$ & $\begin{array}{l}\text { The } \\
\text { Hannan- } \\
\text { Quinn } \\
\text { criterion }\end{array}$ & $\begin{array}{l}\text { Stationarity } \\
\text { and reversibility }\end{array}$ & $\begin{array}{l}\text { Autocorre } \\
\text {-lation }\end{array}$ \\
\hline 1 & $\begin{array}{l}\text { AR } 1,2,6 \\
\text { MA } 1,2,8\end{array}$ & 120.6056 & 140.6041 & 128.6702 & + & + \\
\hline 2 & $\begin{array}{l}\text { AR } 1,2,10 \\
\text { MA } 1,2,8\end{array}$ & 118.8823 & 138.8808 & 126.9469 & + & + \\
\hline 3 & $\begin{array}{l}\text { AR 1, 2, } 11 \\
\text { MA } 1,2,8\end{array}$ & 113.7447 & 133.7432 & 121.8093 & + & - \\
\hline 4 & $\begin{array}{l}\text { AR } 1,2,13 \\
\text { MA } 1,2,13\end{array}$ & 120.3758 & 140.3743 & 128.4404 & + & - \\
\hline 5 & $\begin{array}{l}\text { AR } 1,2,13 \\
\text { MA } 1,2,14\end{array}$ & 120.3757 & 140.3742 & 128.4403 & + & - \\
\hline 6 & $\begin{array}{l}\text { AR 1, 2, } 14 \\
\text { MA 1,2,14 }\end{array}$ & 120.5493 & 140.5478 & 128.6139 & + & - \\
\hline 7 & $\begin{array}{l}\text { AR } 1,2,14 \\
\text { MA } 1,2,8\end{array}$ & 117.7205 & 137.7190 & 125.7851 & + & - \\
\hline 8 & $\begin{array}{l}\text { AR 1,2,6 } \\
\text { MA } 1,2,13\end{array}$ & 120.4676 & 140.4661 & 128.5321 & + & + \\
\hline 9 & $\begin{array}{l}\text { AR } 1,2,10 \\
\text { MA } 1,2,13\end{array}$ & 120.2760 & 140.2745 & 128.3406 & + & + \\
\hline 10 & $\begin{array}{l}\text { AR 1, 2, } 11 \\
\text { MA 1, 2, } 13\end{array}$ & 113.8076 & 133.8061 & 121.8722 & + & - \\
\hline
\end{tabular}

Source : compiled by the author

The model of vector autoregression was also considered, the Granger causality was determined and, accordingly, the presence of cointegrative relations was determined. To select the order of lags, the maximum order of 24 was taken, since the data presented is monthly. All information criteria indicate a lag equal to 2 . Not only inflation, but also the key rate was taken as an endogenous variable, since, as was said earlier, the selected parameters also affect the key rate. To check the correctness of the model, a number of tests were carried out, which confirmed the stationarity of the model and the absence of autocorrelation.

The presence of Granger causality was determined by the F-test for zero constraints from the constructed VAR(2) model. The calculated p-values show that the lags of the key rate and other variables, namely the dollar exchange rate, GDP and money supply, help to predict the current values for the inflation rate, but not vice versa. These same exogenous variables help predict the values of the key rate. Thus, a series of $d_{-} r$ and a series of exogenous 
variables are the Granger cause for d_I, and a series of exogenous variables are also the Granger cause ford_r. Since the opposite does not work, we can conclude that there is a weak exogenicity. Based on the fact that mathematically it was revealed the causality of the rate for the inflation rate, there was an attempt to build a model in which the key rate would be an exogenous variable, but the attempt was considered unsuccessful, since the values of the information criteria significantly decreased. The models for the key rate and the inflation rate were also considered separately, since the variables the dollar exchange rate, GDP and money supply are the reason for Granger for both series, but the quality of the models also decreased compared to the original one.

Based on the current situation, we considered the presence of cointegration relations using the Ingle-Granger test. Based on the p-value obtained in step 5: testing the unit root for uhat, it was concluded that there is no cointegration. This hypothesis was confirmed by the Johansen test.

The results of the test for the presence of redundant variables in the VAR(2) model indicate the possibility of excluding all exogenous variables from the model. However, it is worth noting that the level of information criteria has decreased, but only slightly, therefore, the quality of the model cannot be called critically lost. Thus, the resulting model can be considered final and build a forecast for the inflation rate.

Since the initial series were non-stationary and the model was built on the first differences, the resulting forecast result indicates a further decrease in the inflation rate by 0.06 . The $95 \%$ confidence forecast has a very large range from -0.81 to 0.7 . However, these values approximately coincide with those obtained earlier, so we can assume that the forecast will be correct.

Thus, the study revealed that the dollar exchange rate, GDP and the money supply affect the key rate, and it, in turn, affects the inflation rate. However, these exogenous variables also affect inflation. The level of inflation and the value of the key rate cannot be called interdependent, since the reverse causality according to Granger or co-integration relations were not found. The final model is a VAR (2) consisting of endogenous variables of the inflation rate and the key rate.

\section{Conclusions}

The conducted econometric analysis proves the importance of non-monetary factors of inflation. This makes it difficult to assess the current monetary policy, since the Bank of Russia is able to influence non-monetary factors only indirectly through the main instruments of monetary policy.

Using an econometric model, the inflation rate was predicted. A comparison of the forecast value for April 2021 with the actual inflation, taking into account the 95\% confidence interval, allows us to recognize the approbation of the chosen model as successful and further use it to predict the inflation rate in the Russian economy.

\section{References}

1. Altig, D., Baker, S., Barrero, J. M., Bloom, N., Bunn, P., Chen, S., Davis, S. J., Leather, J., Meyer, B., Mihaylov, E., Mizen, P., Parker, N., Renault, T., Smietanka, P., \& Thwaites, G. (2020). Economic uncertainty before and during the COVID-19 pandemic, Journal of Public Economics, 191, 104274.

2. Auerbach, A. J., Gorodnichenko, Y., \& Murphy, D. (2021). Inequality, fiscal policy and COVID19 restrictions in a demand-determined economy, European Economic Review, $137,103810$. 
3. Braunerhjelm, P. (2021). Rethinking stabilization policies; Including supply-side measures and entrepreneurial processes. Small Bus Econ, https://proxy.library.spbu.ru:2060/10.1007/s11187-021-00520-6

4. Felipe, J., \& Fullwiler, S. (2021) How 'Monetization' Really Works — Examples from Three Asian Nations' Responses to Covid-19, Review of Political Economy.

5. Hossain, A. A., \& Arwatchanakarn, P. (2016). Inflation and inflation volatility in Thailand, Applied Economics, 48(30), 2792-2806.

6. Informacionno-analiticheskij kommentarij Banka Rossii (2021). Inflyacionnye ozhidaniya i potrebitel'skie nastroeniya, 3 (51), 1 (In Russ.)

7. Iyke, B. N., \& Ho, S.-Y. (2019). Inflation, Inflation Uncertainty, and Growth: Evidence from Ghana, Contemporary Economics, 13(2), 123-136.

8. Konyahina O. N. (2020). Metody i instrumenty denezhno-kreditnoj politiki, Forum. Seriya: Gumanitarnye i ekonomicheskie nauki, 3, 138-143 (In Russ.)

9. Kotcofana, T., Altunyan, A., \& Bazzhina, V. (2020) The impact of monopolism on the stability of economic development in the conditions of globalization, SHS Web Conf., 7406013.

10. Leach, M., MacGregor, H., Scoones, I., \& Wilkinson, A. (2021). Post-pandemic transformations: How and why COVID-19 requires us to rethink development, World Development, 138, 105233.

11. Moiseev, S. R. (2018). Nezavisimost' Central'nogo banka: koncepciya, metody ocenki i vliyanie global'nogo finansovogo krizisa, ZHurnal Novoj ekonomicheskoj associacii, 4(40), 111 (In Russ.).

12. Petrova D.A., \& Trunin P.V. (2019). Ocenka inflyacionnyh ozhidanij domohozyajstv, Ekonomicheskoe razvitie Rossii, 3 (In Russ.).

13. Pitelin A. K. (2015). O nemonetarnyh faktorah inflyacii, Ekonomika i matematicheskie metody, 51(1), 45-67. (In Russ.).

14. Ybrayev, Z. (2021). Distributional Consequences of Monetary Policy in Emerging Economies: Dollarization, Domestic Inflation, and Income Divergence. Comp Econ Stud, https://proxy.library.spbu.ru:2060/10.1057/s41294-021-00163-2

15. Zhemkov M. I. (2019). Regional effects of inflation targeting in Russia: Factors of heterogeneity and structural inflation rates. Voprosy Ekonomiki, 9, 70-89. (In Russ.). 